Article

\title{
Targeted Clinical Metabolite Profiling Platform for the Stratification of Diabetic Patients
}

\author{
Linda Ahonen ${ }^{1,+}{ }^{(0)}$, Sirkku Jäntti ${ }^{2}$, Tommi Suvitaival ${ }^{1}{ }^{\circledR}$, Simone Theilade ${ }^{1}$, Claudia Risz ${ }^{1}$, \\ Risto Kostiainen $^{2} \mathbb{D}$, Peter Rossing ${ }^{1,3}$, Matej Orešič ${ }^{4,5}$ iD and Tuulia Hyötyläinen ${ }^{6, *}$ (D) \\ 1 Steno Diabetes Center Copenhagen, 2820 Gentofte, Denmark; la@biosyntia.com (L.A.); \\ tommi.raimo.leo.suvitaival@regionh.dk (T.S.); stheilade@hotmail.com (S.T.); claudia.risz@chello.at (C.R.); \\ peter.rossing@regionh.dk (P.R.) \\ 2 Drug Research Program, Division of Pharmaceutical Chemistry and Technology, Faculty of Pharmacy, \\ University of Helsinki, 00014 Helsinki, Finland; sirkku.e.jantti@gmail.com (S.J.); \\ risto.kostiainen@helsinki.fi (R.K.) \\ 3 Department of Clinical Medicine, University of Copenhagen, 1165 Copenhagen, Denmark \\ 4 Turku Centre for Biotechnology, University of Turku and Åbo Akademi University, 20520 Turku, Finland; \\ matej.oresic@oru.se \\ 5 School of Medical Sciences, Örebro University, 70281 Örebro, Sweden \\ 6 Department of Chemistry, Örebro University, 70281 Örebro, Sweden \\ * Correspondence: tuulia.hyotylainen@oru.se; Tel.: +46-70-7882165 \\ + Current affiliation: Biosyntia ApS, 2100 Copenhagen, Denmark.
}

Received: 1 August 2019; Accepted: 11 September 2019; Published: 14 September 2019

\begin{abstract}
Several small molecule biomarkers have been reported in the literature for prediction and diagnosis of (pre)diabetes, its co-morbidities, and complications. Here, we report the development and validation of a novel, quantitative method for the determination of a selected panel of 34 metabolite biomarkers from human plasma. We selected a panel of metabolites indicative of various clinically-relevant pathogenic stages of diabetes. We combined these candidate biomarkers into a single ultra-high-performance liquid chromatography-tandem mass spectrometry (UHPLC-MS/MS) method and optimized it, prioritizing simplicity of sample preparation and time needed for analysis, enabling high-throughput analysis in clinical laboratory settings. We validated the method in terms of limits of detection (LOD) and quantitation (LOQ), linearity $\left(R^{2}\right)$, and intra- and inter-day repeatability of each metabolite. The method's performance was demonstrated in the analysis of selected samples from a diabetes cohort study. Metabolite levels were associated with clinical measurements and kidney complications in type 1 diabetes (T1D) patients. Specifically, both amino acids and amino acid-related analytes, as well as specific bile acids, were associated with macro-albuminuria. Additionally, specific bile acids were associated with glycemic control, anti-hypertensive medication, statin medication, and clinical lipid measurements. The developed analytical method is suitable for robust determination of selected plasma metabolites in the diabetes clinic.
\end{abstract}

Keywords: clinical diagnostics; diabetes; metabolomics; mass spectrometry

\section{Introduction}

The incidence of type 2 diabetes (T2D) is rising globally, currently estimated to exceed 450 million patients worldwide. In addition, the prevalence of prediabetes is approximately two to three times higher than for diabetes. Prediabetes is a condition with a high risk of progression to T2D, with a yearly conversion rate of $5-10 \%[1,2]$. It is also known that excessive hepatic fat accumulation is a typical feature of T2D patients and plays an important, pathogenic role in disease development and progression. Particularly, non-alcoholic fatty liver disease (NAFLD) may have an important, deleterious 
impact on diabetic patients, increasing the risk of cardiovascular complications. Moreover, there is evidence of associations between prediabetes and complications of diabetes such as early nephropathy, small fiber neuropathy, early retinopathy, and risk of macrovascular disease [2]. Therefore, there is a need for predictive tools for efficient and accurate tracking of the progression from the state of normal glucose tolerance (NGT) to prediabetes and finally to T2D, as well as a need for the identification of those individuals with T1D and T2D who are at risk of developing diabetic complications. There is also a need for improved stratification of those individuals who already have the disease based on their risk of developing complications. Finally, there is a pressing need to then tailor intervention strategies to these individuals. Ideally, knowledge about the underlying pathophysiological characteristics associated with either fasting or postprandial glucose dysregulation would be utilized in order to optimize the efficacy of any interventions [3].

The complex etiology of diabetes makes effective screening, diagnosis, prognosis, and intervention challenging [4]. Several studies have shown changes in the circulating levels of specific metabolites prior to an individual developing overt T2D. For example, the Framingham Offspring, European Investigation into Cancer and Nutrition (EPIC) Potsdam, Metabolic Syndrome in Men (METSIM), Cardiovascular Risk in Young Finns (CRY), and Southall and Brent Revisited (SABRE) studies have replicated the finding of increased levels of branched-chain amino acids and their derivatives, aromatic amino acids, even years ahead of conversion to overt T2D [5-10]. Amino acids, particularly tyrosine, were found to be associated with risk of microvascular disease [11]. Additionally, other metabolites (e.g., 1,5-anhydroglucitol, norvaline and 1-aspartic acid) were found to be associated with macroalbuminuric diabetic kidney disease [12,13], while glutamine, glutamic acid, and symmetric dimethylarginine (ADMA) were suggested as potentially-predictive biomarkers of diabetic complications [14-16]. Several metabolites (e.g., $\beta$-hydroxypyruvate and 1,5-anhydroglucitol (1,5-AG)), were associated with regulation of glycemic control $[17,18]$. Many lipids were identified as predictive biomarkers of diabetes. Specifically, triglycerides of low carbon number and double-bond count as well as lysophosphatidylcholine, LPC(18:2), were identified as early predictors of T2D [19,20]. Notably, these markers were unaffected by obesity [19]. Additionally, bile acids has been associated with T2D and insulin resistance [21,22]. Mannose [23], 2-aminoadipic acid [24,25], as well as indoxyl-sulfate and cresyl-sulfate [26] were suggested as possible biomarkers and creatinine [27] is already routinely implemented as an estimate of renal function. In addition to creatinine, several other metabolites, mainly amino acids and lipids, have been suggested as specific biomarkers for early diagnosis and assessment of the diabetic kidney disease (DKD), as summarized in a recent meta-analysis [28,29].

Most of the studies described above have been performed with non-targeted metabolomics methods, using workflows which are difficult to apply in routine clinical laboratory settings. Herein, our goal was to develop a fast and robust method for quantitative analysis of a selected panel of metabolite biomarkers, which are informative as to the prediction and diagnosis of (pre)diabetes and its co-morbidities/complications, as well as in follow-up of interventions. We developed a method which includes 34 metabolites, representing several metabolite classes, including amino acids, bile acids, carnitines, phenolic compounds, and small organic acids. The method is based on simple sample preparation and fast, quantitative ultra-high-performance liquid chromatography coupled to tandem mass spectrometry (UHPLC-MS/MS) analysis. Both sample preparation and the subsequent analyses were optimized and validated. Additionally, the method was demonstrated in a subset of samples from a cohort of diabetic patients, who were observed at the Steno Diabetes Center Copenhagen between 2009 and 2011 [30].

\section{Results}

Based on our earlier diabetes-related studies, as well as on the results published in the literature, we selected 34 specific metabolites for this study (Table 1, Supplementary Materials, Figures S1-S3) $[2,5-8,10,11,14,17-21,23,24,28,31-34]$. Our aim was to develop a robust and fast analytical assay in terms of both sample preparation and analysis, for quantitative determination of these selected 
metabolites. However, analyzing both highly polar and nonpolar metabolites in a single method is highly problematic. As some of the candidate biomarkers (e.g., very polar sugar derivatives and neutral lipids such as triacylglycerols) would have required a second sample preparation step and/or analytical method, these were excluded from the final method. The method was validated in terms of (a) limit of detection (LOD), (b) limit of quantitation (LOQ), (c) linearity $\left(R^{2}\right)$ and linear range, and (d) intra- and inter-day repeatability of each analyte.

Table 1. Standard compounds acquired for quality control and for quantitation.

\begin{tabular}{|c|c|c|c|c|}
\hline Compound & Abbreviation & Group & Vendor & Solvent, Stock Solution \\
\hline L-Glutamine & Gln & \multirow{16}{*}{$\begin{array}{c}\text { Amino acids + } \\
\text { related } \\
\text { metabolites }\end{array}$} & & $\mathrm{H}_{2} \mathrm{O}$ \\
\hline Glycine & Gly & & & \multirow{15}{*}{$0.1 \mathrm{M} \mathrm{HCl}$} \\
\hline L-Alanine & Ala & & & \\
\hline L-Leucine & Leu & & & \\
\hline L-Isoleucine & Ile & & Sigma-Aldrich & \\
\hline L-Phenylalanine & Phe & & & \\
\hline L-Tryptophan & $\operatorname{Trp}$ & & & \\
\hline L-Tyrosine & Tyr & & & \\
\hline L-Glutamic Acid & Glu & & & \\
\hline L-Citrulline & Cit & & & \\
\hline L-Homocitrulline & HCit & & \multirow{3}{*}{ SCB } & \\
\hline Asymmetric dimethylarginine & ADMA & & & \\
\hline Symmetric dimethylarginine & SDMA & & & \\
\hline DL-2-Aminoadipic Acid & AADA & & \multirow{3}{*}{ Sigma-Aldrich } & \\
\hline L-Kynurenine & Kynu & & & \\
\hline Taurine & Taurine & & & \\
\hline Deoxycholic Acid & DCA & \multirow{12}{*}{ Bile acids } & & \multirow{12}{*}{$\mathrm{MeOH}$} \\
\hline Glycochenodeoxycholic Acid & GCDCA & & & \\
\hline Glycodeoxycholic Acid & GDCA & & & \\
\hline Glycocholic Acid & GCA & & & \\
\hline Taurodeoxycholic Acid & TDCA & & Sigma-Aldrich & \\
\hline Taurochenodeoxycholic Acid & TCDCA & & & \\
\hline Deoxychenocholic Acid & CDCA & & & \\
\hline Cholic Acid & CA & & & \\
\hline Taurocholic Acid & TCA & & & \\
\hline Glycoursodeoxycholic Acid & GUDCA & & \multirow{3}{*}{ CIL } & \\
\hline Ursodeoxycholic Acid & UDCA & & & \\
\hline Tauroursodeoxycholic Acid & TUDCA & & & \\
\hline Creatinine & Crea & \multirow{4}{*}{$\begin{array}{c}\text { Other } \\
\text { metabolites }\end{array}$} & Sigma-Aldrich & \multirow{4}{*}{$10 \% \mathrm{MeOH}$} \\
\hline Indoxyl Sulfate & IndS & & & \\
\hline N-methyl-nicotinamide & N-MNA & & \multirow{2}{*}{ SCB } & \\
\hline Gamma-butyrobetaine & GBB & & & \\
\hline Azelaic Acid & AzelA & \multirow{4}{*}{$\begin{array}{l}\text { Small organic } \\
\text { acids }\end{array}$} & \multirow{4}{*}{ Sigma-Aldrich } & $\mathrm{MeOH}$ \\
\hline L-3-hydroxybutyric Acid & $\beta-\mathrm{OHB}$ & & & \multirow{3}{*}{$10 \% \mathrm{MeOH}$} \\
\hline R-2-hydroxybutyric Acid & $\alpha(\mathrm{R})-\mathrm{OHB}$ & & & \\
\hline S-2-hydroxybutyric Acid & $\alpha(\mathrm{S})-\mathrm{OHB}$ & & & \\
\hline
\end{tabular}

Vendor information: Sigma-Aldrich (Steinheim, Germany); SCB: Santa Cruz Biotechnology, Inc. (Dallas, TX, USA); CIL: Cambridge Isotope Laboratories Inc. (Tewksbury, MA, USA).

\subsection{Sample Preparation}

Here, we combined a simple protein precipitation with acid followed by derivatization of amino acids and structurally-related compounds (Figure S4). For the protein precipitation, acidic conditions were chosen, as protein precipitation with methanol or acetonitrile would have required evaporation of the solvent prior to derivatization and analysis. The amount of derivatization reagent, the amount and type of the solvent and buffer as well as the time for the derivatization reaction were optimized. 
Since the derivatization reagent has an impact on the MS detection, the conditions were optimized to decrease ion suppression as well as to improve the overall robustness of the method. Dry ACN was used for dissolving the AQC-reagent, as even trace amounts of water in the solvent can react with the reagent. The final sample preparation conditions included protein precipitation with SSA, followed by neutralization and $\mathrm{pH}$ adjustment using a mixture of carbonate buffer and $\mathrm{NaOH}$ ) prior to the derivatization with AQC in anhydrous ACN. The MS spectra showed that only amino acids and related compounds with amino acid functionality (namely the amino acids, AADA, ADMA, SDMA, kynurenine, and taurine) were derivatized and not any of the other targeted compounds.

\subsection{LC-MS}

MS- and MS/MS-spectra were acquired for each of the analytes in order to select optimal precursor and product ions for selected reaction monitoring (SRM) analyses (Figures S5-S9). Depending on the ionization properties of the different analytes, protonated $\left([\mathrm{M}+\mathrm{H}]^{+}\right)$or deprotonated $\left([\mathrm{M}-\mathrm{H}]^{-}\right)$ molecules were chosen as precursor ions. MS/MS-spectra were acquired and the most selective and intense product ions were selected for SRM analyses. When possible, one ion transition was chosen for quantification and another ion transition was chosen as the qualifying ion transition to ensure correct measurements of the analytes. Finally, the analysis parameters (fragmentor voltage, collision energy, cell accelerator voltage) were optimized for each ion transition (Table 2). All the derivatized amino acids and related compounds produced the product ion $[\mathrm{M}-\mathrm{H}-170]^{-}$. These were then selected for SRM analyses together with one other diagnostic product ion (where possible). Among the bile acids, CDCA and UDCA were not fragmented and; therefore, the only chosen product ions for these two analytes were their deprotonated molecules. For isomeric compounds (GCDCA, GDCA, and GUDCA; TCDCA, TDCA, and TUDCA) the MS and MS/MS-spectra are similar to the same three main product ions and their separation depends on chromatographic separation. In addition, TCA shows the same three main product ions as TCDCA, TDCA, and TUDCA, but has different precursor ions.

In the optimization of the LC-MS method, different columns (Ascentis Express RP-Amide, Poroshell 120 SB-AQ, Acclaim RSLC PolarAdvantage, Acclaim Trinity P2, and Kinetex ${ }^{\circledR}$ F5 column) and different LC modes were tested. Based on the resolution of the chromatographic separation, the Kinete ${ }^{\circledR}$ F5 column was chosen for further optimization. The conditions were optimized to include sufficient retention for the most polar compounds, and a short overall analysis time. Therefore, the gradient elution was initiated at $99 \%$ of the aqueous eluent. The UHPLC method showed good chromatographic performance (Figure 1), fulfilling general acceptance criteria for an analytical method (Section 4.4). For a few of the analytes, the resolution was; however, insufficient to achieve baseline separation and due to very similar MS/MS-spectra these metabolites (Leu and Ile, TDCA and TCDCA, GCDCA, and GDCA, ADMA, and SDMA) were quantified together. 
Table 2. Optimized fragmentor voltages, collision energies (CE), and cell accelerator voltages for each ion transition of the analytes and internal standards. The ion transition used for quantification is marked with an *

\begin{tabular}{|c|c|c|c|c|c|c|}
\hline Compound & $\begin{array}{l}\text { Molecular Weight } \\
\text { (MW) }\end{array}$ & Ion Transition & Polarity & Fragmentor Voltage (V) & Collision Energy (V) & Cell Accelerator Voltage (V) \\
\hline AADA & 161.2 & $330.2-160.1$ & Negative & 150 & 10 & 1 \\
\hline \multirow{2}{*}{ ADMA and SDMA } & \multirow{2}{*}{202.3} & $371.2-201.2$ * & Negative & 150 & 5 & 5 \\
\hline & & $371.2-156.1$ & Negative & 150 & 20 & 1 \\
\hline Ala & 89.1 & $258.1-88.1$ & Negative & 100 & 15 & 3 \\
\hline \multirow{2}{*}{ AzelA } & \multirow{2}{*}{188.2} & $187.2-169$ & Negative & 150 & 10 & 1 \\
\hline & & $187.2-125.2 *$ & Negative & 150 & 15 & 1 \\
\hline$\beta-\mathrm{OHB}$ & 104.1 & $103.2-59.2$ & Negative & 100 & 5 & 1 \\
\hline \multirow{2}{*}{ CA } & \multirow{2}{*}{408.6} & $407.3-407.3^{*}$ & Negative & 250 & 0 & 1 \\
\hline & & $407.3-343.3$ & Negative & 250 & 35 & 3 \\
\hline CDCA & 392.6 & 391.3-391.3 & Negative & 250 & 0 & 3 \\
\hline Cit & 175.2 & $344.4-174.2$ & Negative & 150 & 4 & 7 \\
\hline \multirow{2}{*}{ Crea } & \multirow{2}{*}{113.1} & $114.1-86.2$ & Positive & 150 & 11 & 4 \\
\hline & & $114.1-44.1$ * & Positive & 150 & 15 & 4 \\
\hline \multirow{2}{*}{ DCA } & \multirow{2}{*}{392.6} & $391.2-345.3$ * & Negative & 200 & 35 & 4 \\
\hline & & $391.2-327.2$ & Negative & 200 & 40 & 4 \\
\hline \multirow{2}{*}{ GBB } & \multirow{2}{*}{146.2} & $147.2-88.1^{*}$ & Positive & 100 & 16 & 1 \\
\hline & & $147.2-60.2$ & Positive & 100 & 13 & 1 \\
\hline \multirow{2}{*}{ GCA } & \multirow{2}{*}{465.6} & $464.3-402.1$ & Negative & 250 & 40 & 4 \\
\hline & & $464.3-74.1^{*}$ & Negative & 250 & 45 & 7 \\
\hline GCDCA & 449.6 & $448.3-386.3$ & Negative & 150 & 40 & 2 \\
\hline GDCA & 449.6 & $448.3-402.1$ & Negative & 250 & 40 & 2 \\
\hline GCDCA and GDCA & 449.6 & $448.3-74.2$ & Negative & 200 & 55 & 2 \\
\hline Gln & 146.1 & $315.3-145.1$ & Negative & 100 & 9 & 6 \\
\hline
\end{tabular}


Table 2. Cont.

\begin{tabular}{|c|c|c|c|c|c|c|}
\hline Compound & $\begin{array}{c}\text { Molecular Weight } \\
\text { (MW) }\end{array}$ & Ion Transition & Polarity & Fragmentor Voltage (V) & Collision Energy (V) & Cell Accelerator Voltage (V) \\
\hline Glu & 147.1 & $316.1-146.1$ & Negative & 100 & 6 & 6 \\
\hline Gly & 75.1 & $244.1-74.1$ & Negative & 200 & 7 & 4 \\
\hline \multirow{2}{*}{ GUDCA } & \multirow{2}{*}{449.6} & $448.3-386$ & Negative & 250 & 40 & 2 \\
\hline & & $448.3-74.1$ * & Negative & 250 & 45 & 2 \\
\hline \multirow{2}{*}{ HCit } & \multirow{2}{*}{189.2} & $358.3-188.1$ & Negative & 200 & 10 & 1 \\
\hline & & $358.3-145 *$ & Negative & 150 & 25 & 2 \\
\hline \multirow{2}{*}{ IndS } & \multirow{2}{*}{213.2} & $212-132$ * & Negative & 100 & 15 & 2 \\
\hline & & $212-80$ & Negative & 100 & 20 & 2 \\
\hline \multirow{2}{*}{ Kynu } & \multirow{2}{*}{208.2} & $377-316.1$ & Negative & 150 & 5 & 2 \\
\hline & & $377-207$ * & Negative & 150 & 5 & 5 \\
\hline Leu and Ile & 131.2 & $300.2-130.2$ & Negative & 100 & 10 & 1 \\
\hline \multirow{2}{*}{ N-MNA } & \multirow{2}{*}{136.2} & $137.1-108.1$ & Positive & 100 & 15 & 2 \\
\hline & & $137.1-80.2$ * & Positive & 100 & 26 & 2 \\
\hline Phe & 165.2 & $334.2-164$ & Negative & 100 & 10 & 1 \\
\hline \multirow{2}{*}{ Taurine } & \multirow{2}{*}{125.2} & $294.1-124.1$ * & Negative & 100 & 10 & 2 \\
\hline & & $294.1-80.1$ & Negative & 100 & 55 & 2 \\
\hline \multirow{2}{*}{ TCA } & \multirow{2}{*}{515.7} & $514.3-123.8$ & Negative & 300 & 65 & 5 \\
\hline & & $514.3-80.2 *$ & Negative & 300 & 95 & 1 \\
\hline \multirow{2}{*}{ TDCA and TCDCA } & \multirow{2}{*}{499.3} & $498.3-107.1$ & Negative & 250 & 80 & 1 \\
\hline & & $498.3-80.1^{*}$ & Negative & 300 & 90 & 1 \\
\hline $\operatorname{Trp}$ & 204.2 & $373.2-203.1$ & Negative & 150 & 7 & 2 \\
\hline \multirow{2}{*}{ TUDCA } & \multirow{2}{*}{499.7} & $498.3-107.1$ & Negative & 300 & 65 & 5 \\
\hline & & $498.3-80.1$ * & Negative & 300 & 85 & 1 \\
\hline
\end{tabular}


Table 2. Cont

\begin{tabular}{|c|c|c|c|c|c|c|}
\hline Compound & $\begin{array}{l}\text { Molecular Weight } \\
\text { (MW) }\end{array}$ & Ion Transition & Polarity & Fragmentor Voltage (V) & Collision Energy (V) & Cell Accelerator Voltage (V) \\
\hline Tyr & 181.2 & $350.2-180.1$ & Negative & 100 & 7 & 5 \\
\hline AADA-d3 & 164.2 & $333.2-145.2$ & Negative & 100 & 20 & 2 \\
\hline ADMA-d7 & 209.8 & $378-208.3$ & Negative & 100 & 10 & 5 \\
\hline Ala-d4 & 93.1 & $262.1-92.1$ & Negative & 100 & 5 & 6 \\
\hline$\alpha-\mathrm{OHB}-\mathrm{d} 3$ & 107.1 & $106.1-59.1$ & Negative & 100 & 10 & 1 \\
\hline AzelA-d14 & 202.3 & $201.2-137.2$ & Negative & 150 & 10 & 2 \\
\hline$\beta-\mathrm{OHB}-\mathrm{d} 4$ & 108.1 & $107.1-59.1$ & Negative & 100 & 5 & 1 \\
\hline CA-d4 & 412.3 & $411.3-411.3$ & Negative & 250 & 0 & 3 \\
\hline $\begin{array}{l}\text { CDCA-d } 4 \text { and } \\
\text { DCA-d } 4\end{array}$ & 396.6 & $395.2-395.2$ & Negative & 300 & 0 & 4 \\
\hline Cit-d4 & 179.2 & $348.1-135.1$ & Negative & 100 & 25 & 2 \\
\hline Crea-d5 & 118.2 & $119.2-49.3$ & Positive & 100 & 20 & 1 \\
\hline GBB-d9 & 154.7 & $155.2-87.3$ & Positive & 100 & 15 & 6 \\
\hline GCA-d4 & 469.6 & $468.3-74.1$ & Negative & 250 & 45 & 1 \\
\hline $\begin{array}{l}\text { GCDCA-d4 and } \\
\text { GUDCA-d4 }\end{array}$ & 453.6 & $452.3-74.1$ & Negative & 250 & 40 & 1 \\
\hline GDCA-d6 & 455.7 & $454.3-408.2$ & Negative & 250 & 55 & 4 \\
\hline Gln-d5 & 151.2 & 320.1-150.1 & Negative & 100 & 5 & 1 \\
\hline Glu-d5 & 152.1 & $321.1-151.1$ & Negative & 100 & 5 & 1 \\
\hline Gly-13C,d2 & 78.1 & 247-77.1 & Negative & 100 & 5 & 7 \\
\hline HCit-2H4 & 193.2 & $362.2-192.2$ & Negative & 100 & 5 & 6 \\
\hline IndS-d4 & 217.3 & 216-136.1 & Negative & 100 & 15 & 2 \\
\hline Kynu-13C6 & 214.2 & $383.1-195.8$ & Negative & 100 & 10 & 6 \\
\hline
\end{tabular}


Table 2. Cont

\begin{tabular}{|c|c|c|c|c|c|c|}
\hline Compound & $\begin{array}{c}\text { Molecular Weight } \\
\text { (MW) }\end{array}$ & Ion Transition & Polarity & Fragmentor Voltage (V) & Collision Energy (V) & Cell Accelerator Voltage (V) \\
\hline Leu-d10 and Ile-d10 & 141.2 & $310.1-140$ & Negative & 125 & 10 & 2 \\
\hline N-MNA-d4 & 140.2 & $141.2-84.2$ & Positive & 100 & 20 & 7 \\
\hline Phe-d5 & 170.2 & $339.1-169.1$ & Negative & 150 & 5 & 1 \\
\hline Taurine-d4 & 129.2 & $298.3-128.2$ & Negative & 100 & 10 & 3 \\
\hline TCA-d4 & 519.7 & $518.3-80$ & Negative & 340 & 100 & 7 \\
\hline TCDCA-d9 & 508.3 & $507.4-80.1$ & Negative & 300 & 95 & 1 \\
\hline Trp-d8 & 212.3 & $381.2-211.2$ & Negative & 100 & 10 & 5 \\
\hline TUDCA-d4 & 503.7 & $502.3-80.1$ & Negative & 300 & 100 & 1 \\
\hline Tyr-d7 & 188.2 & $357.1-187.2$ & Negative & 100 & 10 & 1 \\
\hline UDCA-d4 & 396.6 & $395.3-395.3$ & Negative & 250 & 0 & 4 \\
\hline
\end{tabular}




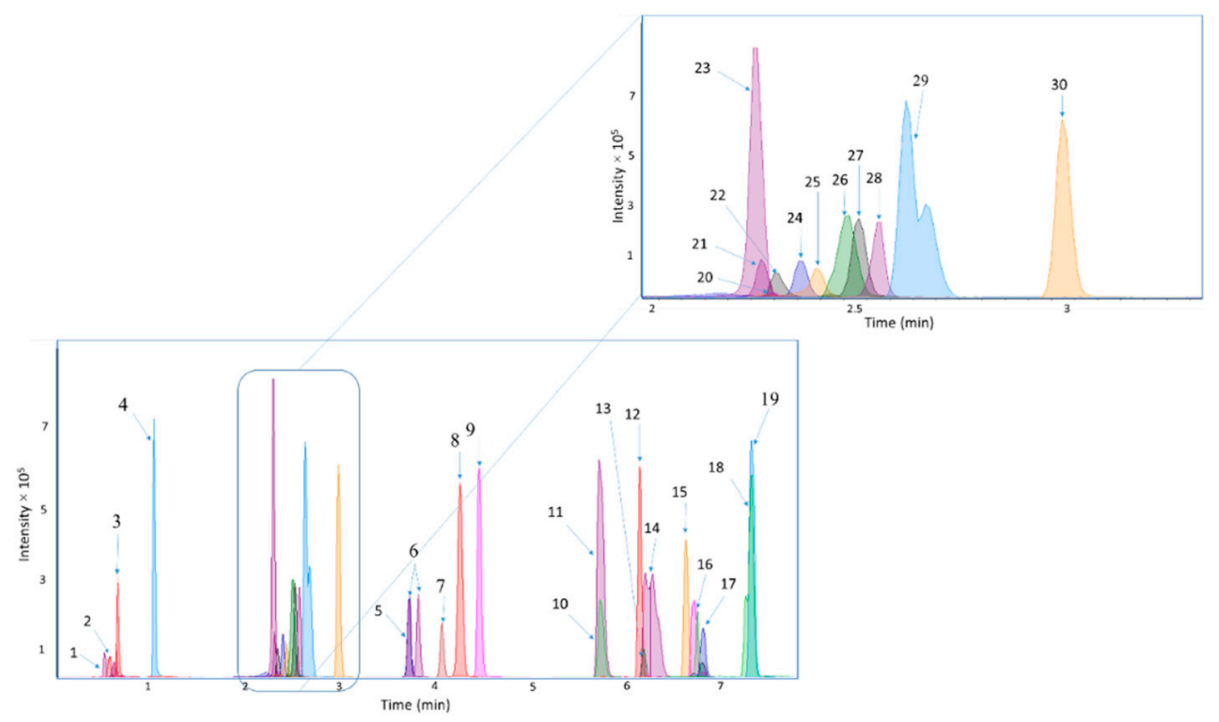

Figure 1. Chromatograms representing the chromatographic separation of the analytes. The peak numbers correspond to the following analytes: (1) Crea, (2) GBB, (3) $\beta-\mathrm{OHB}$, (4) N-MNA, (4) Kynu, (6) Leu and Ile, (7) Phe, (8) AzelA, (9) Trp, (10) TUDCA, (11) TCA, (12) GCA, (13) GUDCA, (14) TDCA and TCDCA, (15) CA, (16) CDCA, (17) GCDCA and GDCA, (18) UDCA, (19) DCA, (20) Gly, (21) Gln,

(22) ADMA and SDMA, (23) taurine, (24) Phe, (25) Gln, (26) HCit, (27) Ala, (28) AADA, (29) IndS and (30) Tyr.

\subsection{Method Validation}

The quantitative performance of the developed UHPLC-ESI-MS/MS method was evaluated with respect to (a) limit of detection (LOD), (b) limits of quantitation (LOQ), (c) linearity $\left(R^{2}\right)$ and linear range, and (d) intra- and inter-day repeatability (Table 4). LOQs were determined as the lower and upper limits of quantitation (LLOQ and ULOQ), reported also as linear range, according to guidelines of International Council for Harmonisation of Technical Requirements for Pharmaceuticals for Human Use (ICH). The LODs (at $S / N \geq 3$ ) were measured from standard samples and are remarkably different for different analytes, with the lowest LOD being $<2.5 \mathrm{ng} \mathrm{mL}^{-1}$ (being the lowest measured concentration) for Ala, AzelA, GCDCA, GDCA, Leu, Ile, N-MNA, Phe, and TCA. These results indicate an acceptable sensitivity, as the typical concentrations of the target compounds in human blood samples have a large range and the sensitivity of the method developed here is within the concentration ranges normally detected in blood samples [35]. Calibration curves and the intra- and inter-day repeatability were determined by using normalized peak areas. For the analytes which were quantified together (i.e., GCDCA and GDCA, ADMA and SDMA, and TDCA and TCDCA), only one ISTD was used. The ISTDs used for GCDCA and GDCA, ADMA and SDMA, and TDCA and TCDCA were GDCA-d6, ADMA-d7, and TCDCA-d9, respectively. Additionally, for three analytes (i.e., GBB, Crea, and $\beta-\mathrm{OHB}$ ), the ISTD signal was not repeatable and; therefore, the validation parameters of these analytes were measured without normalization to an ISTD. The calibration curves were determined within a concentration range of $2.5-75,000 \mathrm{ng} \mathrm{mL}^{-1}$. The linear ranges showed a broad variation between the different analytes (Table 3). The coefficients of determination $\left(R^{2}\right)$ were within the accuracy demand of $80-120 \%$ and they were higher than 0.97 for all analytes and above 0.99 for most analytes. 
Table 3. Linearity $\left(R^{2}\right)$ with lower and upper limits of detection (LLOD and ULLOQ), linear range, repeatability of retention times (Rt) and intra- and inter-day repeatability of concentrations at different concentrations.

\begin{tabular}{|c|c|c|c|c|c|c|c|c|c|c|}
\hline \multirow{2}{*}{ Compound } & \multirow{2}{*}{$\begin{array}{l}\text { Linearity }\left(R^{2}\right) \text { Range } \\
\text { (LLOQ-ULOQ) } \\
\left(\text { ng } \mathrm{mL}^{-1}\right)\end{array}$} & \multirow{2}{*}{$\begin{array}{c}\text { LOD } \\
\left(\mathrm{ng} / \mathrm{mL}^{-1}\right)\end{array}$} & \multirow{2}{*}{$\begin{array}{l}\text { \%RSD_Rt, } \\
\text { Intra-Day }\end{array}$} & \multicolumn{3}{|c|}{ \%RSD_Area, Intra-Day $(N=4)$} & \multirow{2}{*}{$\begin{array}{l}\text { \%RSD_Rt, } \\
\text { Inter-Day }\end{array}$} & \multicolumn{3}{|c|}{ \%RSD_Area, Inter-Day $(N=15)$} \\
\hline & & & & $100 \mathrm{ng} \mathrm{mL}^{-1}$ & $1000 \mathrm{ng} \mathrm{mL}^{-1}$ & $10,000 \mathrm{ng} \mathrm{mL}^{-1}$ & & $100 \mathrm{ng} \mathrm{mL}^{-1}$ & $1000 \mathrm{ng} \mathrm{mL}^{-1}$ & $10,000 \mathrm{ng} \mathrm{mL}^{-1}$ \\
\hline AADA & $\begin{array}{c}0.984 \\
5000-75,000\end{array}$ & 500 & $\begin{array}{c}0.2 \\
(N=4)\end{array}$ & - & - & 9.1 & $\begin{array}{c}0.1 \\
(N=15)\end{array}$ & - & - & 8.7 \\
\hline $\begin{array}{l}\text { ADMA and } \\
\text { SDMA }\end{array}$ & $\begin{array}{c}0.992 \\
2500-50,000\end{array}$ & 500 & $\begin{array}{c}0.2 \\
(N=8)\end{array}$ & - & 5.6 & 0.8 & $\begin{array}{c}0.2 \\
(N=30)\end{array}$ & - & 8.5 & 4.2 \\
\hline Ala & $\begin{array}{c}0.996 \\
500-50,000\end{array}$ & $<2.5$ & $\begin{array}{c}0.2 \\
(N=8)\end{array}$ & - & 4.5 & 3.0 & $\begin{array}{c}0.1 \\
(N=30)\end{array}$ & - & 9.8 & 13.6 \\
\hline AzelA & $\begin{array}{c}0.995 \\
500-10,000\end{array}$ & $<2.5$ & $\begin{array}{c}0.5 \\
(N=8)\end{array}$ & - & 11.4 & 3.9 & - & - & 15.8 & 8.4 \\
\hline$\beta-\mathrm{OHB}$ & $\begin{array}{c}0.970 \\
2500-75,000\end{array}$ & 75 & $\begin{array}{c}0.6 \\
(N=4)\end{array}$ & - & - & 20.9 & $\begin{array}{c}1.2 \\
(N=15)\end{array}$ & - & - & 24.5 \\
\hline CA & $\begin{array}{c}0.996 \\
10-10,000\end{array}$ & 7.5 & $\begin{array}{c}0.2 \\
(N=12)\end{array}$ & 2.4 & 3.1 & 5.2 & $\begin{array}{c}0.7 \\
(N=45)\end{array}$ & 20.8 & 18.1 & 20.2 \\
\hline CDCA & $\begin{array}{c}0.999 \\
25-2500\end{array}$ & 7.5 & $\begin{array}{c}0.2 \\
(N=8)\end{array}$ & 4.0 & 4.9 & - & $\begin{array}{c}0.2 \\
(N=45)\end{array}$ & 4.3 & 5.1 & 14.2 \\
\hline Cit & $\begin{array}{c}0.984 \\
500-10,000\end{array}$ & 250 & $\begin{array}{c}0.2 \\
(N=8)\end{array}$ & - & 7.7 & 6.7 & $\begin{array}{c}0.2 \\
(N=30)\end{array}$ & - & 9.1 & 8.3 \\
\hline Crea & $\begin{array}{c}0.973 \\
250-7500\end{array}$ & 25 & $\begin{array}{c}0.8 \\
(N=4)\end{array}$ & - & 17.8 & - & $\begin{array}{c}0.0 \\
(N=15)\end{array}$ & - & 3.5 & - \\
\hline DCA & $\begin{array}{c}0.996 \\
5-2500 \\
\end{array}$ & 2.5 & $\begin{array}{c}0.2 \\
(N=8)\end{array}$ & 5.8 & 6.1 & - & $\begin{array}{c}0.3 \\
(N=30) \\
\end{array}$ & 4.3 & 8.3 & - \\
\hline GBB & $\begin{array}{c}0.974 \\
250-10,000\end{array}$ & 50 & $\begin{array}{c}0.5 \\
(N=8)\end{array}$ & - & 18.7 & 15.9 & $\begin{array}{c}1.5 \\
(N=30)\end{array}$ & - & 27.3 & 28.5 \\
\hline GCA & $\begin{array}{c}0.997 \\
50-25,000 \\
\end{array}$ & 25 & $\begin{array}{c}0.1 \\
(N=12)\end{array}$ & 4.6 & 4.2 & 4.2 & $\begin{array}{c}0.4 \\
(N=45)\end{array}$ & 6.8 & 5.1 & 7.3 \\
\hline $\begin{array}{l}\text { GCDCA and } \\
\text { GDCA }\end{array}$ & $\begin{array}{c}0.997 \\
25-2500\end{array}$ & $<2.5$ & $\begin{array}{c}0.2 \\
(N=8)\end{array}$ & 1.9 & 4.2 & - & $\begin{array}{c}0.5 \\
(N=30)\end{array}$ & 16.4 & 16.1 & - \\
\hline Gln & $\begin{array}{c}0.987 \\
750-50,000\end{array}$ & 5 & $\begin{array}{c}0.1 \\
(N=8)\end{array}$ & - & 5.0 & 7.7 & $\begin{array}{c}0.5 \\
(N=30)\end{array}$ & - & 10.5 & 11.5 \\
\hline Glu & $\begin{array}{c}0.990 \\
750-75,000\end{array}$ & 500 & $\begin{array}{c}0.2 \\
(N=8)\end{array}$ & - & 13.9 & 10.7 & $\begin{array}{c}0.3 \\
(N=30)\end{array}$ & - & 10.9 & 5.2 \\
\hline
\end{tabular}


Table 3. Cont.

\begin{tabular}{|c|c|c|c|c|c|c|c|c|c|c|}
\hline \multirow{2}{*}{ Compound } & \multirow{2}{*}{$\begin{array}{c}\text { Linearity }\left(R^{2}\right) \text { Range } \\
\text { (LLOQ-ULOQ) } \\
\left(\mathrm{ng} \mathrm{mL}^{-1}\right)\end{array}$} & \multirow{2}{*}{$\begin{array}{c}\text { LOD } \\
\left(\mathrm{ng} / \mathrm{mL}^{-1}\right)\end{array}$} & \multirow{2}{*}{$\begin{array}{l}\text { \%RSD_Rt, } \\
\text { Intra-Day }\end{array}$} & \multicolumn{3}{|c|}{ \%RSD_Area, Intra-Day $(N=4)$} & \multirow{2}{*}{$\begin{array}{l}\text { \%RSD_Rt, } \\
\text { Inter-Day }\end{array}$} & \multicolumn{3}{|c|}{ \%RSD_Area, Inter-Day $(N=15)$} \\
\hline & & & & $100 \mathrm{ng} \mathrm{mL}^{-1}$ & $1000 \mathrm{ng} \mathrm{mL}^{-1}$ & $10,000 \mathrm{ng} \mathrm{mL}^{-1}$ & & $100 \mathrm{ng} \mathrm{mL}^{-1}$ & $1000 \mathrm{ng} \mathrm{mL}^{-1}$ & $10,000 \mathrm{ng} \mathrm{mL}^{-1}$ \\
\hline Gly & $\begin{array}{c}0.993 \\
7500-75,000\end{array}$ & 1000 & $\begin{array}{c}0.03 \\
(N=4)\end{array}$ & - & - & 16.2 & $\begin{array}{c}0.6 \\
(N=15)\end{array}$ & - & - & 19.6 \\
\hline GUDCA & $\begin{array}{c}0.994 \\
75-10,000 \\
\end{array}$ & 25 & $\begin{array}{c}0.1 \\
(N=12)\end{array}$ & 5.0 & 9.0 & 10.6 & $\begin{array}{c}0.3 \\
(N=45)\end{array}$ & 13.1 & 10.9 & 6.2 \\
\hline HCit & $\begin{array}{c}0.995 \\
500-25,000\end{array}$ & 250 & $\begin{array}{c}0.2 \\
(N=8)\end{array}$ & - & 8.3 & 2.6 & $\begin{array}{c}0.5 \\
(N=30)\end{array}$ & - & 11.1 & 16.4 \\
\hline IndS & $\begin{array}{c}0.986 \\
5000-75,000\end{array}$ & 750 & $\begin{array}{c}0.3 \\
(N=4)\end{array}$ & - & - & 11.3 & $\begin{array}{c}0.3 \\
(N=15)\end{array}$ & - & - & 15.4 \\
\hline Kynu & $\begin{array}{c}0.993 \\
500-75,000 \\
\end{array}$ & 250 & $\begin{array}{c}0.2 \\
(N=8)\end{array}$ & - & 11.2 & 7.4 & $\begin{array}{c}0.4 \\
(N=30)\end{array}$ & - & 7.7 & 4.4 \\
\hline Leu and Ile & $\begin{array}{c}0.997 \\
25-75,000 \\
\end{array}$ & $<2.5$ & $\begin{array}{c}0.4 \\
(N=12)\end{array}$ & 4.6 & 4.3 & 1.5 & $\begin{array}{c}0.5 \\
(N=45)\end{array}$ & 13.0 & 14.0 & 5.7 \\
\hline N-MNA & $\begin{array}{c}0.998 \\
25-10,000\end{array}$ & $<2.5$ & $\begin{array}{c}0.5 \\
(N=12)\end{array}$ & 1.6 & 6.4 & 3.7 & $\begin{array}{c}1.0 \\
(N=45)\end{array}$ & 20.1 & 18.5 & 6.5 \\
\hline Phe & $\begin{array}{c}0.995 \\
250-25,000\end{array}$ & $<2.5$ & $\begin{array}{c}0.4(N= \\
0.4)\end{array}$ & - & 5.9 & 6.6 & $\begin{array}{c}0.4 \\
(N=30)\end{array}$ & - & 10.1 & 4.6 \\
\hline Taurine & $\begin{array}{c}0.994 \\
250-25,000\end{array}$ & 10 & $\begin{array}{c}0.2 \\
(N=8)\end{array}$ & - & 8.3 & 5.7 & $\begin{array}{c}0.5 \\
(N=30)\end{array}$ & - & 8.4 & 8.7 \\
\hline TCA & $\begin{array}{c}0.983 \\
2500-25,000\end{array}$ & $<2.5$ & $\begin{array}{c}0.1 \\
(N=4)\end{array}$ & - & - & 4.5 & $\begin{array}{c}0.3 \\
(N=15)\end{array}$ & - & - & 15.5 \\
\hline $\begin{array}{l}\text { TDCA and } \\
\text { TCDCA }\end{array}$ & $\begin{array}{c}0.984 \\
1000-25,000\end{array}$ & 10 & $\begin{array}{c}0.7 \\
(N=8)\end{array}$ & - & 0.4 & 5.7 & $\begin{array}{c}0.7 \\
(N=30)\end{array}$ & - & 2.6 & 4.2 \\
\hline $\operatorname{Trp}$ & $\begin{array}{c}0.996 \\
25-25,000 \\
\end{array}$ & 25 & $\begin{array}{c}0.4 \\
(N=12)\end{array}$ & 9.0 & 2.9 & 4.7 & $\begin{array}{c}0.5 \\
(N=45)\end{array}$ & 18.8 & 5.4 & 5.3 \\
\hline TUDCA & $\begin{array}{c}0.990 \\
250-10,000 \\
\end{array}$ & 10 & $\begin{array}{c}0.1 \\
(N=8)\end{array}$ & - & 5.5 & 4.5 & $\begin{array}{c}0.7 \\
(N=30)\end{array}$ & - & 1.8 & 3.0 \\
\hline Tyr & $\begin{array}{c}0.992 \\
50-75,000\end{array}$ & 25 & $\begin{array}{c}0.2 \\
(N=12)\end{array}$ & 10.3 & 9.1 & 4.4 & $\begin{array}{c}0.3 \\
(N=45)\end{array}$ & 5.7 & 8.4 & 3.4 \\
\hline UDCA & $\begin{array}{c}0.991 \\
50-50,000\end{array}$ & 25 & $\begin{array}{c}0.2 \\
(N=12)\end{array}$ & 1.5 & 3.5 & 3.3 & $\begin{array}{c}0.2 \\
(N=45)\end{array}$ & 3.5 & 10.3 & 5.6 \\
\hline
\end{tabular}


For the repeatability studies, three standard samples $\left(c=100,1000\right.$, and $\left.10,000 \mathrm{ng} \mathrm{mL}^{-1}\right)$ were analyzed in four consecutive runs and in three runs on five consecutive days for intra-day and inter-day repeatability measurements, respectively. Relative standard deviations (\%RSD) were calculated for both the intra- and inter-day studies (Table 3). The \%RSDs for the intra-day repeatability studies were generally below $1.5 \%$ and $20.8 \%$ for the retention times and normalized peak area ratios, respectively. There are a few exceptions to these results for the analytes with no internal standards (Crea, GBB, and $\beta-\mathrm{OHB}$ ). The $\%$ RSDs for the intra- and inter-day repeatability for these three analytes was between $17.8 \%$ and $20.9 \%$ and between $3.5 \%$ and $24.5 \%$, respectively.

\subsection{Feasibility of the Method for the Analysis of Samples from a Diabetes Cohort}

In total, 50 samples were selected from a previously-described study cohort of a total of 676 participants who has a wide range of albuminuria [36]. The subset was created with computational sampling, aiming at finding a small random subset of the cohort, where the distributions of potentially confounding clinical variables are as similar as possible between the two study groups. This allowed us to study associations between metabolites and albuminuria even in this small sample set whilst avoiding the confounding effects of other factors. The clinical variables assessed were age, antihypertensive medication, BMI, duration of diabetes, glycated hemoglobin (HbA1c), insulin day dose, sex, smoking, systolic blood pressure, total cholesterol, and total triglycerides.

Selection of the best random subsample was done in four steps: (1) In total, 1 million $N=25+25$ sub-samples were drawn with random sampling, (2) the correlation between each clinical variable and the albuminuria group variable was computed for each subsample, (3) the highest absolute value of correlation in each subsample was identified, and (4) the random subsample with the lowest value of maximum correlation was selected for being the least-confounded random subset for analysis.

Computational selection resulted in a balanced subset of samples from 25 normo-albuminuric and 25 macro-albuminuric participants. The highest Pearson correlation to the albuminuria group variable among the clinical variables was 0.21 for total triglycerides. All other clinical variables had a lower absolute correlation to the group variable, suggesting that the selected small subset was not confounded by imbalance in the clinical characteristics.

Associations between metabolite concentrations and relevant clinical variables were tested with metabolite-specific mixed-effects models using the R-package limma [37]. Metabolite concentrations entered the model as the dependent variable, participant identity as the random effect and the following clinical variables as fixed effects: albuminuria group, age, BMI, estimated globular filtration rate (eGFR; kidney function), glycated hemoglobin (HbA1c; glycemic control), sex, systolic blood pressure, total cholesterol, total triglycerides. Significance tests of coefficients were corrected for multiple testing over the metabolites with the Benjamini-Hochberg method [38].

Associations indicated by significant model coefficients (multiple-testing-corrected $p<0.05$ ) were visualized as a bipartite network (Figure 2) between clinical variables and metabolites with the R-package ggplot2 [39]. Strength (log-10-transformed coefficients) and the signs of each association were shown in the width and the color of the line, respectively. Metabolomic associations to albuminuria group and eGFR, which are the key variables of the present study, were highlighted with opaque lines. 


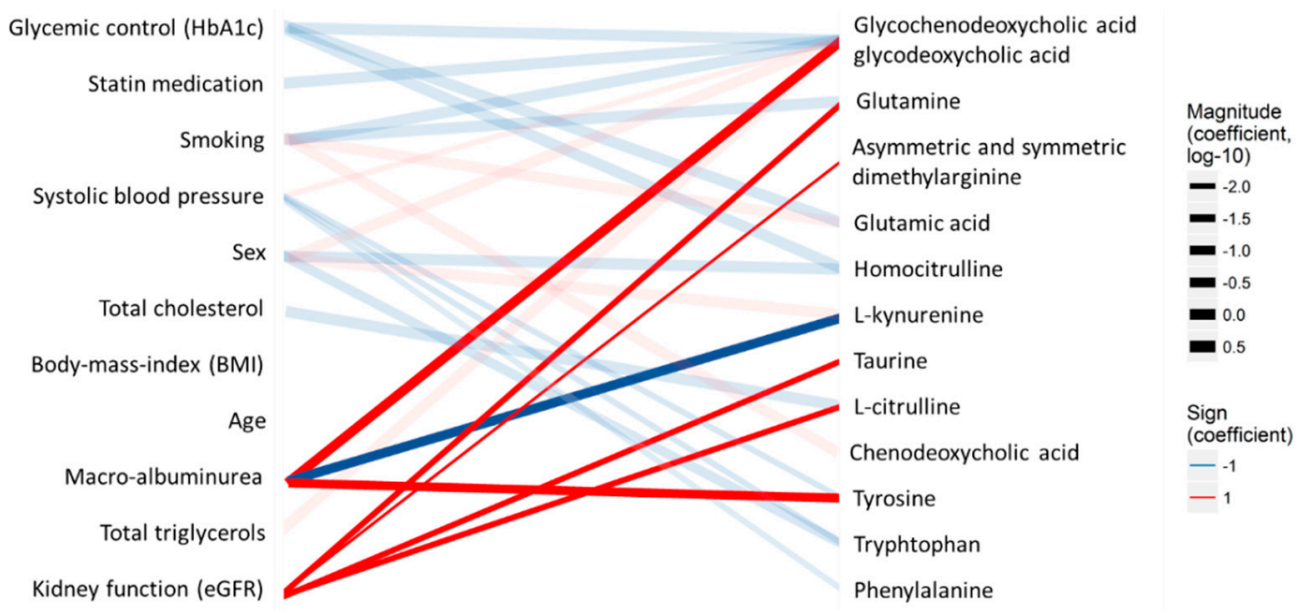

Figure 2. Associations between clinical measurements (left) and the quantified analytes (right) in the type 1 diabetes T1D cohort. The lines indicate statistical associations (red-positive association and blue-inverse/opposite association; line width—strength of the association). Associations directly related to diabetic kidney disease are highlighted with bold lines.

The target panel included metabolites which have previously been associated particularly with kidney functions. The analysis resulted in concentrations of the measured metabolites in 50 participants with T1D. For the statistical analyses, only metabolites that were detected in over $70 \%$ of the samples were included, resulting in 20 metabolites. Macro-albuminuria, which is an indicator of kidney disease, was associated with elevated GCDCA and GDCA, Tyr, Trp, and decreased Kynu (Table 4, Figure 2). Estimated globular filtration rate (eGFR; kidney function), was associated with ADMA and SDMA, Cit, Gln, taurine, and Tyr. Glycated hemoglobin ( $\mathrm{HbA1c}$; glucose control) was associated with decreased GCDCA and GCDA, Glu, and HCit. Smoking was associated with elevated Glu and decreased Gln as well as to a disruption in the balance of the bile acids GCDCA and GDCA. Although no metabolomic associations were found with age or BMI in this small sub-study, several metabolites were associated with sex, statin medication, systolic blood pressure, total cholesterol, and total triglycerides. It should; however, be noted that as our target panel is based on reported markers of (pre)diabetes and diabetic complications, and does not cover the entire metabolome, a comprehensive pathway analysis could be biased and not fully reliable. The quantitative results are presented in Table 4.

Table 4. Concentrations of metabolites in the validation cohort and their $p$ values.

\begin{tabular}{ccccc}
\hline Metabolite Name & $\begin{array}{c}\text { Normo-Albuminuria, } \\
\text { Mean c (Standard } \\
\text { Deviation) }\end{array}$ & $\begin{array}{c}\text { Macro-Albuminuria, } \\
\text { Mean c (Standard } \\
\text { Deviation) }\end{array}$ & $p$ Value & adj. $p$ Value \\
\hline $\begin{array}{c}\text { Glycochenodeoxycholic } \\
\text { Acid and } \\
\text { Glycodeoxycholic Acid }\end{array}$ & $4.33(11.74)$ & $2.10(6.58)$ & 0.00012 & 0.0021 \\
\hline L-Kynurenine & $383.23(249.28)$ & $309.03(86.53)$ & 0.00043 & 0.0034 \\
\hline Tyrosine & $6185.75(1865.87)$ & $7012.51(2076.69)$ & 0.00057 & 0.0034 \\
\hline Tryptophan & $5913.04(1705.38)$ & $6388.34(1346.28)$ & 0.031 & 0.14 \\
\hline $\begin{array}{c}\text { Asymmetric } \\
\text { dimethylarginine and } \\
\text { Symmetric }\end{array}$ & $165.73(51.07)$ & $153.35(18.60)$ & 0.26 & 0.57 \\
Dimethylarginine & $6393.48(3159.65)$ & $7303.02(3656.17)$ & 0.28 & 0.57 \\
\hline Leucine and Isoleucine & $1101.07(7.10)$ & $1099.58(6.38)$ & 0.29 & 0.57 \\
\hline Chenodeoxycholic Acid & $9696.30(5174.24)$ & $10,313.80(3604.96)$ & 0.32 & 0.58 \\
\hline Glycine & & & & \\
\hline
\end{tabular}


Table 4. Cont.

\begin{tabular}{ccccc}
\hline Metabolite Name & $\begin{array}{c}\text { Normo-Albuminuria, } \\
\text { Mean c (Standard } \\
\text { Deviation) }\end{array}$ & $\begin{array}{c}\text { Macro-Albuminuria, } \\
\text { Mean c (Standard } \\
\text { Deviation) }\end{array}$ & $\boldsymbol{p}$ Value & adj. $\boldsymbol{p}$ Value \\
\hline Glutamine & $31,651.43(8920.90)$ & $29,020.85(6798.27)$ & 0.4 & 0.63 \\
\hline L-Citrulline & $2235.88(1160.64)$ & $2253.08(852.27)$ & 0.42 & 0.63 \\
\hline Alanine & $16,925.72(4875.55)$ & $16,087.19(3345.81)$ & 0.58 & 0.75 \\
\hline Indoxyl Sulfate & $907.87(493.53)$ & $920.80(561.30)$ & 0.6 & 0.75 \\
\hline Homocitrulline & $11.36(25.76)$ & $10.21(20.90)$ & 0.62 & 0.75 \\
\hline Taurine & $4741.00(2046.23)$ & $4128.35(1424.84)$ & 0.77 & 0.86 \\
\hline Phenylalanine & $9337.50(2600.13)$ & $8949.64(2062.99)$ & 0.86 & 0.91 \\
\hline Glutamic Acid & $8164.60(3588.71)$ & $9304.01(7562.67)$ & 0.93 & 0.93 \\
\hline
\end{tabular}

\section{Discussion}

The main goal in the selection of conditions for sample preparation was the development of a workflow that is simple, robust, and feasible to automate, while taking into consideration the LC-MS method as well. The optimized sample preparation procedure, including the derivatization of amino acids and related compounds, was fast, and, by optimization of the solvent composition, we could improve the sensitivity and robustness of the derivatization step in comparison with the conventional derivatization procedures. Overall, the sample preparation is very fast, as the derivatization takes place immediately after addition of the reagent and all steps of the sample preparation can be done with automated robotic sample preparation systems. The advantage of the derivatization is that it increases the retention of the amino acids and thus allows the use of reversed-phase LC, which is more robust than, for example, hydrophilic interaction chromatography, particularly when the goal is to simultaneously analyze very polar (e.g., small amino acids) and relatively non-polar compounds (e.g., bile acids).

The linear range of the method as well as the LODs were in the range of the biological concentrations typically detected in blood-based samples. This shows that the method has both good linearity and quantitation ability for each analyte, with accuracies well within the general requirement of $80-120 \%$. Moreover, the method developed here proved to be fast (with a sample analysis time of less than $10 \mathrm{~min}$ ) and robust. Thus, in terms of throughput, the method is suitable for large-scale analysis. Currently, LC-MS techniques are applied in endocrinology, screening for inborn errors of metabolism, therapeutic drug monitoring/toxicology confirmation, vitamin analysis, and, more recently, the peptide and protein quantitation [40]. It should be noted that introducing a LC-MS/MS method into patient care requires that the methodology should undergo rigorous and systematic validation, including all steps of the analytical workflow, starting from the chemicals, solvent quality, columns and maintenance of the system to data processing and interpretation, in addition to traditional validation parameters that have been covered here. It should be also noted that trained personnel is a prerequisite in the use of LC-MS in clinical laboratory.

The feasibility of the developed UHPLC-ESI-MS/MS method for the analysis of biological samples was demonstrated by analyzing plasma samples from individuals with diabetes who had a wide range of albuminuria. Albuminuria is a pathological condition where the protein albumin is present in the urine in abnormal amounts. In healthy subjects (normo-albuminuric), only trace amounts of albumin $(<30 \mathrm{mg} / 24 \mathrm{~h})$ are present in the urine while subjects with elevated amounts of albumin in the urine, on the other hand, can be classified as either micro-albuminuric (c=30-299 mg/24 h) or macro-albuminuric ( $\geq 300 \mathrm{mg} / 24 \mathrm{~h}$ ) [41]. Albuminuria is a sign of diabetic kidney disease, which often occurs especially in subjects with type 1 diabetes [36,41,42]. In type 2 diabetes (T2D), microalbuminuria is an independent risk factor for the prevalence of diabetic retinopathy $[42,43]$. In the 
general population, predictors of incident albuminuria include age, male sex, smoking, and low HDL cholesterol level [44].

Several target metabolites showed either up- or downregulation in the T1D patients with albuminuria, although not all differences reached statistical significance. More specifically, we observed that several of the metabolites showed statistical associations related to the measured kidney functions and eGFR. We observed alterations in many of the amino acids measured, although not all changes reached statistical significance. Our results agree with a recent study that showed altered plasma amino acid profiles in DKD, showing that tyrosine was significantly increased in T2D patients with microalbuminuria [45]. Tyrosine has, in a recent meta-analysis, been shown to be one of the risk factors for T2D with 36\% increased risk [46]. Several studies have indicated that abnormal amino acids levels are associated with diabetic kidney disease, although with somewhat contrary patterns of amino acids $[28,35,45,47]$. Indeed, changed amino acids metabolites might actually be more contributable to the dysregulated renal filtration state, which is unlikely to be revealed in the early pathologies of DKD, as suggested in a recent systematic review of metabolic biomarkers of DKD [28]. We also observed associations between the eGFR and ADMA, glutamine, taurine, and citrulline, in agreement of several previous studies $[16,48]$. Particularly, ADMA has been suggested as a candidate biomarker for diabetic kidney complications, whilst elevated levels of ADMA have been shown to predict a more accelerated course of renal function loss and promoted the development of renal damage [15,16,48]. Bile acids which have important roles as signaling molecules controlling glucose, lipid, and energy metabolism were significantly different in subjects with macro-albuminuria, and they were further associated with glycemic control. Altered bile acid metabolism has been observed particularly in T2D patients [49], but there are no earlier studies of bile acids metabolism in subjects with albuminuria. Interestingly, the main possible confounders previously linked with albuminuria, both in the general population and in diabetic patients, such as smoking, sex, or age, showed no significant associations with the metabolites most strongly linked with macro-albuminuria or kidney functions. Overall, our results suggest that the developed analytical method is feasible for performing targeted metabolomic analysis of plasma samples from diabetic patients, and that it can be used for more accurate stratification of diabetic patients-making it; thus, suitable for the use in the diabetes clinic.

Validation of the method showed that the selected panel of markers can be effectively used for classification of subjects with diabetic complications, such as macro-albuminuria. However, several of the metabolites in the current panel are related to a wide range of complications, both in T1D and T2D. Further evaluation of the clinical relevance of the method is clearly needed, in order to evaluate the full potential of this diagnostic panel in the stratification of prediabetes, metabolic, and diabetic complications.

\section{Materials and Methods}

\subsection{Chemicals and Standard Solutions}

LC-MS grade water $\left(\mathrm{H}_{2} \mathrm{O}\right)$, methanol $(\mathrm{MeOH})$, isopropanol (IPA), and acetonitrile (ACN) were purchased from Honeywell International Inc. (Morristown, NJ, USA). HPLC grade dichloromethane (DCM), anhydrous ACN, analytical grade formic acid $(\mathrm{HCOOH})$, and reagent grade potassium carbonate $\left(\mathrm{K}_{2} \mathrm{CO}_{3}\right)$, potassium bicarbonate $\left(\mathrm{KHCO}_{3}\right)$, sodium hydroxide $(\mathrm{NaOH})$, hydrochloric acid $(\mathrm{HCl})$, and 5-sulphosalisylic acid dehydrate (SSA) were purchased from Sigma-Aldrich (Steinheim, Germany). 6-aminoquinoline-N-hydroxy-succinimidyl carbamate (AQC) for derivatization of amino acids was purchased from Santa Cruz Biotechnology, Inc. (Dallas, TX, USA).

Stock solutions ( $\left.4.0 \mathrm{mg} \mathrm{mL}^{-1}\right)$ of the analytes and internal standards (Tables 1 and 5) were prepared by dissolving in $0.1 \mathrm{M} \mathrm{HCl}, \mathrm{H}_{2} \mathrm{O}, \mathrm{H}_{2} \mathrm{O}: \mathrm{MeOH}(90: 10, v / v)$ or in $\mathrm{MeOH}$ and further diluting them with $0.6 \mathrm{M}$ carbonate buffer $(\mathrm{pH} 8.9)$ and $1 \mathrm{M} \mathrm{NaOH}(3: 1, v / v)$ (in order to subsequently neutralize and adjust the $\mathrm{pH}$ ) to the following concentration levels: $2.5,5.0,7.5,10.0,25,50,75,100,250,500,750,1000,2500$, $5000,7500,10,000,25,000,50,000$, and $75,000 \mathrm{ng} \mathrm{mL}^{-1}$. A total of $20 \mu \mathrm{L}$ of an internal standard solution 
(ISTD MIX) containing each of the internal standards (Table 5) was added to all samples. The samples were vortex mixed and $20 \mu \mathrm{L}$ of a $5 \mathrm{mg} \mathrm{mL}^{-1}$ AQC-reagent, which was dissolved in anhydrous ACN $\left(\right.$ at $55^{\circ} \mathrm{C}$ ) was added for derivatization of the amino acids and related metabolites (Supplementary Figure S4). Finally, the samples were vortex mixed and stored at $-80{ }^{\circ} \mathrm{C}$ until analysis. The calibration curves were constructed using at least five measuring points and linear regression with $1 / x$ weighing. For $\alpha(\mathrm{R})$-OHB and $\alpha(\mathrm{S})$-OHB, only three measuring points could be used due to the high LOD of these analytes.

Table 5. Internal standards, with concentrations in ISTD MIX, acquired for quality control and for quantitation.

\begin{tabular}{|c|c|c|c|c|c|}
\hline Internal Standard & Abbreviation & Group & Vendor & $\begin{array}{l}\text { Solvent, } \\
\text { Stock } \\
\text { Solution }\end{array}$ & $\begin{array}{c}\text { Concentration } \\
\text { in ISTD MIX } \\
\left(\mathrm{ng} \mathrm{mL}^{-1}\right)\end{array}$ \\
\hline d5-Glutamine & d5-Gln & \multirow{15}{*}{$\begin{array}{c}\text { Amino acids } \\
+ \text { related } \\
\text { metabolites }\end{array}$} & CIL & $\mathrm{H}_{2} \mathrm{O}$ & 30,000 \\
\hline d10-L-Leucine & d10-Leu & & $\mathrm{CDN}$ & & \multirow{6}{*}{5000} \\
\hline${ }^{2} \mathrm{H}_{4}$-L-Homocitrulline & 2H4-HCit & & Alsachim & & \\
\hline Glycine- $1-{ }^{13} \mathrm{C}, 2,2-\mathrm{d}_{2}$ & 13C, d2-Gly & & \multirow{3}{*}{ Sigma-Aldrich } & & \\
\hline d4-DL-Alanine & d4-Ala & & & & \\
\hline d5-L-Glutamic Acid & d5-Glu & & & $01 \mathrm{M} \mathrm{HCl}$ & \\
\hline d10-Isoleucine & d10-Ile & & \multirow{7}{*}{ CIL } & $0.11 V 11 C_{1}$ & \\
\hline d5-L-Phenylalanine & d5-Phe & & & & 500 \\
\hline d8-Tryptophan & d8-Trp & & & & 5000 \\
\hline d7-Tyrosine & d7-Tyr & & & & \\
\hline d4-Citrulline & d4-Cit & & & & 500 \\
\hline d3-L-2-Aminoadipic Acid & d3-AADA & & & & 10,000 \\
\hline d7-Asymmetric dimethylarginine & d7-ADMA & & & & 5000 \\
\hline${ }^{13} \mathrm{C}_{6}-$ Kynurenine & 13C6-Kynu & & \multirow{2}{*}{ Alsachim } & & 30,000 \\
\hline d4-Taurine & d4-Taurine & & & & 500 \\
\hline d4-Deoxycholic Acid & d4-DCA & & \multirow{6}{*}{$\mathrm{CDN}$} & \multirow{11}{*}{$\mathrm{MeOH}$} & 500 \\
\hline d4-Glycocholic Acid & d4-GCA & & & & 250 \\
\hline d4-Deoxychenocholic Acid & d4-CDCA & & & & 500 \\
\hline d4-Glycoursodeoxycholic Acid & d4-GUDCA & Bile acids & & & 5000 \\
\hline d4-Cholic Acid & $\mathrm{d} 4-\mathrm{CA}$ & Dile actus & & & 500 \\
\hline d4-Ursodeoxycholic Acid & d4-UDCA & & & & 250 \\
\hline d4-Glychochenodeoxycholic Acid & d4-GCDCA & & \multirow{5}{*}{ CIL } & & 5000 \\
\hline d6-Glycodeoxycholic Acid & d6-GDCA & & & & 30,000 \\
\hline d9-Taurochenodeoxycholic Acid & d9-TCDCA & & & & \multirow{2}{*}{500} \\
\hline d4-Taurocholic Acid & d4-TCA & & & & \\
\hline d4-Tauroursodeoxycholic Acid & d4-TUDCA & & & & 250 \\
\hline d5-Creatinine & d5-Crea & \multirow{4}{*}{$\begin{array}{c}\text { Polar } \\
\text { metabolites }\end{array}$} & \multirow{3}{*}{$\mathrm{CDN}$} & \multirow{4}{*}{$10 \% \mathrm{MeOH}$} & 10,000 \\
\hline d4-N-methyl-nicotinamide & d4-N-MNA & & & & 250 \\
\hline d9-Gamma-butyrobetaine & d9-GBB & & & & 500 \\
\hline d4-Indoxyl Sulfate & d4-IndS & & Sigma-Aldrich & & 5000 \\
\hline d14-Azelaic Acid & d14-AzelA & \multirow{3}{*}{$\begin{array}{l}\text { Small organic } \\
\text { acids }\end{array}$} & \multirow{3}{*}{$\mathrm{CDN}$} & $\mathrm{MeOH}$ & 5000 \\
\hline d4-3-Hydroxybutyric Acid & $\mathrm{d} 4-\beta-\mathrm{OHB}$ & & & \multirow{2}{*}{$10 \% \mathrm{MeOH}$} & \multirow{2}{*}{100,000} \\
\hline d3-2-Hydroxybutyric Acid & d3- $\alpha-O H B$ & & & & \\
\hline
\end{tabular}




\subsection{Samples}

Plasma samples from a previously-described cohort [30,36] were used for validation of the method. In short, during 2009-2011, a total of 1285 patients were invited to enter a study examining diabetic complications at the Steno Diabetes Center Copenhagen (SDCC). The study conformed to the Declaration of Helsinki and was approved by the Danish National Committee on Biomedical Research Ethics (2009-056; NCT01171248). Additionally, all patients gave written, informed consent. Of the invited 1285 patients, 676 accepted to participate and for our purposes, to demonstrate method functionality, a subset of 50 patient samples was analyzed. In addition to these plasma samples, pooled plasma samples from the SDCC were used for method development and validation as well as for quality control. All plasma samples were stored at $-80^{\circ} \mathrm{C}$ until analysis.

\subsection{Sample Preparation}

Sample preparation included protein precipitation and derivatization (see 4.1. for details of standards, stock solutions and derivatization reagent). A total of $10 \mu \mathrm{L}$ of $1 \mathrm{M} \mathrm{5}$-sulphosalisylic acid dehydrate (SSA) solution was added to $30 \mu \mathrm{L}$ of plasma sample, samples were vortex mixed and centrifuged at $9000 \mathrm{RCF}\left(5 \mathrm{~min}\right.$ at $4{ }^{\circ} \mathrm{C}$ ) after which $20 \mu \mathrm{L}$ of the upper phase was collected. After, addition of $20 \mu \mathrm{L}$ of the ISTD MIX $20 \mu \mathrm{L}$ of a 6-aminoquinoline-N-hydroxy-succinimidyl carbamate-reagent (AQC-reagent) $\left(5 \mathrm{mg} \mathrm{mL}^{-1}\right.$, at $\left.55^{\circ} \mathrm{C}\right)$ was added, and the samples were vortex mixed and stored at $-80^{\circ} \mathrm{C}$ until analysis.

The samples in the validation study were randomized before sample preparation and again before analysis. Calibration curves were created at the beginning and at the end of the sample analyses. Additionally, blank samples and pooled plasma samples were included in the analytical sequence for quality control purposes. Samples were injected three times, resulting in three technical replicate measurements for each of the 50 samples.

\subsection{Ultra High-Performance Liquid Chromatography (UHPLC)-Mass Spectrometry}

The UHPLC system was 1290 Infinity system from Agilent Technologies (Santa Clara, CA, USA) and it was equipped with a multi-sampler (maintained at $10^{\circ} \mathrm{C}$ ), a binary solvent manager, and a column thermostat (maintained at $40{ }^{\circ} \mathrm{C}$ ). The multi-sampler was set to utilize the multi-wash option as the needle wash. Here two mixtures, ACN:MeOH:IPA: $\mathrm{H}_{2} \mathrm{O}(1: 1: 1: 1, v / v / v / v)+0.1 \% \mathrm{HCOOH}$ and $10 \% \mathrm{DCM}$ in $\mathrm{MeOH}$, were used for $8 \mathrm{~s}$ after each injection in order to clean the needle and the needle seat. Finally, the needle and the needle seat were flushed with the initial gradient conditions for $8 \mathrm{~s}$. Separations were performed on a Kinetex ${ }^{\circledR} \mathrm{F} 5$ column $(100 \times 2.1 \mathrm{~mm}$, particle size $1.7 \mu \mathrm{m})$ from Phenomenex (Torrance, CA, USA) with a flow rate of $0.4 \mathrm{~mL} \mathrm{~min}^{-1}$ and an injection volume of $2 \mu \mathrm{L}$. $\mathrm{H}_{2} \mathrm{O}+0.1 \% \mathrm{HCOOH}(\mathrm{A})$ and ACN:IPA $(2: 1, v / v)+0.1 \% \mathrm{HCOOH}(\mathrm{B})$ were used as the mobile phases for gradient elution. The gradient was as follows: from 0 to $1 \mathrm{~min} 1 \% \mathrm{~B}$, from 1 to $1.8 \mathrm{~min} 1-18 \% \mathrm{~B}$, from 1.8 to $3.4 \mathrm{~min} 18-21 \% \mathrm{~B}$, from 3.4 to $7 \mathrm{~min} 21-65 \% \mathrm{~B}$, from 7 to $7.1 \mathrm{~min} 65-100 \% \mathrm{~B}$ and from 7.1 to $8.9 \mathrm{~min} 100 \%$ B. Each run was followed by a $2.5 \mathrm{~min}$ re-equilibration period under initial conditions (1\% B).

The mass spectrometer was a 6460 triple quadrupole system from Agilent Technologies. It was interfaced with an Agilent Jet Stream electrospray ionization source. The analytes were ionized in positive or in negative ion mode depending on the properties of the analyte. Nitrogen generated by a Genius 3010 nitrogen generator from PEAK Scientific Instruments Ltd. (Inchinnan, Scotland, UK) was used as the nebulizing gas (pressure $29 \mathrm{psi}$ ) and as the sheath gas at $250{ }^{\circ} \mathrm{C}$ and $6 \mathrm{~L} \mathrm{~min}^{-1}$ and at $310{ }^{\circ} \mathrm{C}$ and $9 \mathrm{~L} \mathrm{~min}^{-1}$, respectively. Pure nitrogen (6.0) from Praxair (Fredericia, Denmark) was used as the collision gas. The capillary voltage was set to $3000 \mathrm{~V}$ and the nozzle voltage to $1000 \mathrm{~V}$. MS- and MS/MS-spectra (scan range $m / z$ 40-600) were acquired for each analyte to select the best precursor and product ions for selected reaction monitoring (SRM) analyses. The fragmentor voltages, collision energies (CE), and cell accelerator voltages were separately optimized for each ion transition 
of the analytes (Table 3) and the internal standards (Table 4). MassHunter LC/MS Data Acquisition Software (version B.08.02) was used for all data acquisition. For data processing different software were used: MassHunters Quantitative Analysis Software (version B.07.00), Skyline Daily (version 4.1) [50], and R [51].

Data from the diabetes cohort were processed as follows: (i) Peaks were picked in Skyline [50], (ii) resulting peak areas were normalized to matching internal standard peak areas in $R$, and (iii) the resulting peak area ratios were calibrated to concentrations in $\mathrm{R}$ based on metabolite-specific calibration curves run during the analysis sequence.

Supplementary Materials: The following are available online at http://www.mdpi.com/2218-1989/9/9/184/s1, Figure S1: Derivatization reaction. Figure S2: Structures of compounds of interest, amino acids, and amino acid-related compounds, Figure S3: Structures of compounds of interest, bile acids, Figure S4: Structures of compounds of interest, small organic acids and other metabolites of interest, Figure S5: (a) MS-spectrum and (b) MS/MS-spectrum of taurine, Figure S6: (a) MS-spectrum and (b) MS/MS-spectrum of azelaic acid, Figure S7: (a) MS-spectrum and (b) MS/MS-spectrum of gamma-butyrobetaine, Figure S8: (a) MS-spectrum and (b) MS/MS-spectrum of glycolic acid, Figure S9: (a) MS-spectrum and (b) MS/MS-spectrum of L-homocitrulline.

Author Contributions: Conceptualization, T.H. and M.O. methodology S.J., L.A., T.H., M.O., C.R., S.T., P.R. and R.K.; investigation, T.H., M.O., L.A., T.S., writing-original draft preparation, T.H., L.A. and M.O. writing一review and editing, S.J., R.K., P.R., T.S., C.R., and S.T.

Funding: This research received no external funding.

Acknowledgments: We thank Nina Christiansen and Birgitte Nergaard Roberts for assistance with sample preparation and Niina Kärkkäinen for help in the laboratory. We acknowledge Lars Ove Dragsted for valuable input during the final validation of the method. We thank Aidan McGlinchey for language editing. This work was funded by the Novo Nordisk Foundation, grant number NNF14OC0013659 PROTON.

Conflicts of Interest: The authors declare no conflict of interest.

\section{References}

1. Tuso, P. Prediabetes and Lifestyle Modification: Time to Prevent a Preventable Disease. Perm. J. 2014, 18, 88-93. [CrossRef] [PubMed]

2. Bansal, N. Prediabetes diagnosis and treatment: A review. World J. Diabetes 2015, 6, 296-303. [CrossRef] [PubMed]

3. Kristine, F.; Adam, H.; Thomas, P.J.S. Heterogeneity of Pre-diabetes and Type 2 Diabetes: Implications for Prediction, Prevention and Treatment Responsiveness. Curr. Diabetes Rev. 2016, 12, 30-41.

4. Chatterjee, S.; Khunti, K.; Davies, M.J. Type 2 diabetes. Lancet 2017, 389, 2239-2251. [CrossRef]

5. Tillin, T.; Hughes, A.D.; Wang, Q.; Würtz, P.; Ala-Korpela, M.; Sattar, N.; Forouhi, N.G.; Godsland, I.F.; Eastwood, S.V.; McKeigue, P.M.; et al. Diabetes risk and amino acid profiles: Cross-sectional and prospective analyses of ethnicity, amino acids and diabetes in a South Asian and European cohort from the SABRE (Southall And Brent REvisited) Study. Diabetologia 2015, 58, 968-979. [CrossRef]

6. Würtz, P.; Soininen, P.; Kangas, A.J.; Rönnemaa, T.; Lehtimäki, T.; Kähönen, M.; Viikari, J.S.; Raitakari, O.T.; Ala-Korpela, M. Branched-Chain and Aromatic Amino Acids Are Predictors of Insulin Resistance in Young Adults. Diabetes Care 2013, 36, 648-655. [CrossRef] [PubMed]

7. Wang, T.J.; Larson, M.G.; Vasan, R.S.; Cheng, S.; Rhee, E.P.; McCabe, E.; Lewis, G.D.; Fox, C.S.; Jacques, P.F.; Fernandez, C. Metabolite profiles and the risk of developing diabetes. Nat. Med. 2011, 17, 448. [CrossRef]

8. Stančáková, A.; Civelek, M.; Saleem, N.K.; Soininen, P.; Kangas, A.J.; Cederberg, H.; Paananen, J.; Pihlajamäki, J.; Bonnycastle, L.L.; Morken, M.A.; et al. Hyperglycemia and a Common Variant of GCKR Are Associated With the Levels of Eight Amino Acids in 9369 Finnish Men. Diabetes 2012, 61, 1895-1902. [CrossRef]

9. Suvitaival, T.; Mantere, O.; Kieseppä, T.; Mattila, I.; Pöhö, P.; Hyötyläinen, T.; Suvisaari, J.; Orešič, M. Serum metabolite profile associates with the development of metabolic co-morbidities in first-episode psychosis. Transl. Psychiatry 2016, 6, e951. [CrossRef]

10. Floegel, A.; Stefan, N.; Yu, Z.; Mühlenbruch, K.; Drogan, D.; Joost, H.G.; Fritsche, A.; Häring, H.U; de Hrabě Angelis, M.; Peters, A. Identification of Serum Metabolites Associated With Risk of Type 2 Diabetes Using a Targeted Metabolomic Approach. Diabetes 2013, 62, 639-648. [CrossRef] 
11. Welsh, P.; Rankin, N.; Li, Q.; Mark, P.B.; Würtz, P.; Ala-Korpela, M.; Marre, M.; Poulter, N.; Hamet, P.; Chalmers, J. Circulating amino acids and the risk of macrovascular, microvascular and mortality outcomes in individuals with type 2 diabetes: Results from the ADVANCE trial. Diabetologia 2018, 61, 1581-1591. [CrossRef] [PubMed]

12. Tavares, G.; Venturini, G.; Padilha, K.; Zatz, R.; Pereira, A.C.; Thadhani, R.; Rhee, E.P.; Titan, S.M.O. 1,5-Anhydroglucitol predicts CKD progression in macroalbuminuric diabetic kidney disease: Results from non-targeted metabolomics. Metabolomics 2018, 14, 39. [CrossRef] [PubMed]

13. Yu, B.; Zheng, Y.; Nettleton, J.A.; Alexander, D.; Coresh, J.; Boerwinkle, E. Serum metabolomic profiling and incident CKD among African Americans. Clin. J. Am. Soc. Nephrol. 2014, 9, 1410-1417. [CrossRef] [PubMed]

14. Rhee, S.Y.; Jung, E.S.; Park, H.M.; Jeong, S.J.; Kim, K.; Chon, S.; Yu, S.Y.; Woo, J.T.; Lee, C.H. Plasma glutamine and glutamic acid are potential biomarkers for predicting diabetic retinopathy. Metabolomics 2018, 14, 89. [CrossRef] [PubMed]

15. Lajer, M.; Tarnow, L.; Jorsal, A.; Teerlink, T.; Parving, H.H.; Rossing, P. Plasma Concentration of Asymmetric Dimethylarginine (ADMA) Predicts Cardiovascular Morbidity and Mortality in Type 1 Diabetic Patients With Diabetic Nephropathy. Diabetes Care 2008, 31, 747-752. [CrossRef]

16. Zobel, E.H.; von Scholten, B.J.; Reinhard, H.; Persson, F.; Teerlink, T.; Hansen, T.W.; Parving, H.H.; Jacobsen, P.K.; Rossing, P. Symmetric and asymmetric dimethylarginine as risk markers of cardiovascular disease, all-cause mortality and deterioration in kidney function in persons with type 2 diabetes and microalbuminuria. Cardiovasc. Diabetol. 2017, 16, 88. [CrossRef]

17. Yousri, N.A.; Mook-Kanamori, D.O.; Selim, M.M.; Takiddin, A.H.; Al-Homsi, H.; Al-Mahmoud, K.A.; Karoly, E.D.; Krumsiek, J.; Do, K.T.; Neumaier, U. A systems view of type 2 diabetes-associated metabolic perturbations in saliva, blood and urine at different timescales of glycaemic control. Diabetologia 2015, 58, 1855-1867. [CrossRef]

18. Gall, W.E.; Beebe, K.; Lawton, K.A.; Adam, K.P.; Mitchell, M.W.; Nakhle, P.J.; Ryals, J.A.; Milburn, M.V.; Nannipieri, M.; Camastra, S. $\alpha$-Hydroxybutyrate Is an Early Biomarker of Insulin Resistance and Glucose Intolerance in a Nondiabetic Population. PLOS ONE 2010, 5, e10883. [CrossRef]

19. Suvitaival, T.; Bondia-Pons, I.; Yetukuri, L.; Pöhö, P.; Nolan, J.J.; Hyötyläinen, T.; Kuusisto, J.; Orešič, M. Lipidome as a predictive tool in progression to type 2 diabetes in Finnish men. Metabolism 2018, 78, 1-12. [CrossRef]

20. Wang-Sattler, R.; Yu, Z.; Herder, C.; Messias, A.C.; Floegel, A.; He, Y.; Heim, K.; Campillos, M.; Holzapfel, C.; Thorand, B. Novel biomarkers for pre-diabetes identified by metabolomics. Mol. Syst. Biol. 2012, 8, 615. [CrossRef]

21. Carter, T.C.; Rein, D.; Padberg, I.; Peter, E.; Rennefahrt, U.; David, D.E.; McManus, V.; Stefanski, E.; Martin, S.; Schatz, P. Validation of a metabolite panel for early diagnosis of type 2 diabetes. Metabolism 2016, 65, 1399-1408. [CrossRef] [PubMed]

22. Haeusler, R.A.; Astiarraga, B.; Camastra, S.; Accili, D.; Ferrannini, E. Human Insulin Resistance Is Associated With Increased Plasma Levels of $12 \alpha$-Hydroxylated Bile Acids. Diabetes 2013, 62, 4184-4191. [CrossRef] [PubMed]

23. Sone, H.; Shimano, H.; Ebinuma, H.; Takahashi, A.; Yano, Y.; Iida, K.T.; Suzuki, H.; Toyoshima, H.; Kawakami, Y.; Okuda, Y.; et al. Physiological changes in circulating mannose levels in normal, glucoseintolerant, and diabetic subjects. Metabolism 2003, 52, 1019-1027. [CrossRef]

24. Wang, T.J.; Ngo, D.; Psychogios, N.; Dejam, A.; Larson, M.G.; Vasan, R.S.; Ghorbani, A.; O'Sullivan, J.; Cheng, S.; Rhee, E.P.; et al. 2-Aminoadipic acid is a biomarker for diabetes risk. J. Clin. Investig. 2013, 123, 4309-4317. [CrossRef] [PubMed]

25. Klein, M.S.; Shearer, J. Metabolomics and Type 2 Diabetes: Translating Basic Research into Clinical Application. J. Diabetes Res. 2016, 2016, 10. [CrossRef] [PubMed]

26. Barrios, C.; Beaumont, M.; Pallister, T.; Villar, J.; Goodrich, J.K.; Clark, A.; Pascual, J.; Ley, R.E.; Spector, T.D.; Bell, J.T.; et al. Gut-Microbiota-Metabolite Axis in Early Renal Function Decline. PLoS ONE 2015, 10, e0134311. [CrossRef]

27. Kim, S.H.; Lee, K.A.; Jin, H.Y.; Baek, H.S.; Park, T.S. The Relationship between Anemia and the Initiation of Dialysis in Patients with Type 2 Diabetic Nephropathy. Diabetes Metab. J. 2015, 39, 240-246. [CrossRef] [PubMed] 
28. Zhang, Y.; Zhang, S.; Wang, G. Metabolomic biomarkers in diabetic kidney diseases-A systematic review. J. Diabetes Complicat. 2015, 29, 1345-1351. [CrossRef]

29. Percival, B.C.; Grootveld, M.; Gibson, M.; Osman, Y.; Molinari, M.; Jafari, F.; Sahota, T.; Martin, M.; Casanova, F.; Mather, M.L.; et al. Low-Field, Benchtop NMR Spectroscopy as a Potential Tool for Point-of-Care Diagnostics of Metabolic Conditions: Validation, Protocols and Computational Models. High Throughput. 2018, 8, 2. [CrossRef]

30. Theilade, S.; Lajer, M.; Persson, F.; Joergensen, C.; Rossing, P. Arterial Stiffness Is Associated With Cardiovascular, Renal, Retinal, and Autonomic Disease in Type 1 Diabetes. Diabetes Care 2013, 36, 715-721. [CrossRef]

31. Du, M.-R.; Yan, L.; Li, N.S.; Wang, Y.J.; Zhou, T.; Jiang, J.L. Asymmetric dimethylarginine contributes to retinal neovascularization of diabetic retinopathy through EphrinB2 pathway. Vasc. Pharmacol. 2018, 108, 46-56. [CrossRef] [PubMed]

32. Larsen, M.B.; Henriksen, J.E.; Grauslund, J.; Peto, T. Prevalence and risk factors for diabetic retinopathy in 17 152 patients from the island of Funen, Denmark. Acta Ophthalmol. 2017, 95, 778-786. [CrossRef] [PubMed]

33. Arneth, B.; Arneth, R.; Shams, M. Metabolomics of Type 1 and Type 2 Diabetes. Int. J. Mol. Sci. 2019, 20, 2467. [CrossRef] [PubMed]

34. Campion, C.G.; Sanchez-Ferras, O.; Batchu, S.N. Potential Role of Serum and Urinary Biomarkers in Diagnosis and Prognosis of Diabetic Nephropathy. Can. J. Kidney Health Dis. 2017, 4. [CrossRef] [PubMed]

35. Wishart, D.S.; Feunang, Y.D.; Marcu, A.; Guo, A.C.; Liang, K.; Vázquez-Fresno, R.; Sajed, T.; Johnson, D.; Li, C.; Karu, N.; et al. HMDB 4.0: The human metabolome database for 2018. Nucleic Acids Res. 2018, 46, D608-D617. [CrossRef]

36. Theilade, S.; Hansen, T.W.; Goetze, J.P.; Rossing, P. Increased Plasma Concentrations of Midregional Proatrial Natriuretic Peptide Is Associated With Risk of Cardiorenal Dysfunction in Type 1 Diabetes. Am. J. Hypertens. 2015, 28, 772-779. [CrossRef]

37. Ritchie, M.E.; Phipson, B.; Wu, D.; Hu, Y.; Law, C.W.; Shi, W.; Smyth, G.K. Limma powers differential expression analyses for RNA-sequencing and microarray studies. Nucleic Acids Res. 2015, 43, e47. [CrossRef]

38. Benjamini, Y.; Hochberg, Y. Controlling the False Discovery Rate: A Practical and Powerful Approach to MultipleTesting. J. R. Stat. Soc. Ser. B 1995, 57.

39. Wickham, H. Ggplot2: Elegant Graphics for Data Analysis; Springer-Verlag: Berlin/Heidelberg, Germany, 2016.

40. Leung, K.S.-Y.; Fong, B.M.-W.J.A.; Chemistry, B. LC-MS/MS in the routine clinical laboratory: Has its time come? Anal. Bioanal. Chem. 2014, 406, 2289-2301. [CrossRef]

41. Hashemipour, S.; Charkhchian, M.; Javadi, A.; Afaghi, A.; Hajiaghamohamadi, A.A.; Bastani, A.; Hajmanoochehri, F.; Ziaee, A. Urinary total protein as the predictor of albuminuria in diabetic patients. Int. J. Endocrinol. Metab. 2012, 10, 523-526. [CrossRef]

42. Kar, D.; Gillies, C.; Nath, M.; Khunti, K.; Davies, M.J.; Seidu, S. Association of smoking and cardiometabolic parameters with albuminuria in people with type 2 diabetes mellitus: A systematic review and meta-analysis. Acta Diabetol. 2019, 56, 839-850. [CrossRef] [PubMed]

43. Song, K.-H.; Jeong, J.S.; Kim, M.K.; Kwon, H.S.; Baek, K.H.; Ko, S.H.; Ahn, Y.B. Discordance in risk factors for the progression of diabetic retinopathy and diabetic nephropathy in patients with type 2 diabetes mellitus. J. Diabetes Investig. 2019, 10, 745-752. [CrossRef] [PubMed]

44. O'Seaghdha, C.M.; Hwang, S.J.; Upadhyay, A.; Meigs, J.B.; Fox, C.S. Predictors of Incident Albuminuria in the Framingham Offspring Cohort. Am. J. Kidney Dis. 2010, 56, 852-860. [CrossRef] [PubMed]

45. Chuang, W.-H.; Arundhathi, A.; Lu, C.; Chen, Ch.; Wu, Wa.; Susanto, H.; Purnomo, J.D.T.; Wang, C. Altered plasma acylcarnitine and amino acid profiles in type 2 diabetic kidney disease. Metabolomics 2016, 12, 108. [CrossRef]

46. Guasch-Ferre, M.; Hruby, A.; Toledo, E.; Clish, C.B.; Martínez-González, M.A.; Salas-Salvadó, J.; Hu, F.B. Metabolomics in Prediabetes and Diabetes: A Systematic Review and Meta-analysis. Diabetes Care 2016, 39, 14. [CrossRef] [PubMed]

47. Abbiss, H.; Maker, G.L.; Trengove, R.D. Metabolomics Approaches for the Diagnosis and Understanding of Kidney Diseases. Metabolites 2019, 9, 34. [CrossRef]

48. Fliser, D.; Kronenberg, F.; Kielstein, J.T.; Morath, C.; Bode-Böger, S.M.; Haller, H.; Ritz, E. Asymmetric Dimethylarginine and Progression of Chronic Kidney Disease: The Mild to Moderate Kidney Disease Study. J. Am. Soc. Nephrol. 2005, 16, 2456-2461. [CrossRef] 
49. Prawitt, J.; Caron, S.; Staels, B.J.C.D.R. Bile Acid Metabolism and the Pathogenesis of Type 2 Diabetes. Curr. Diab. Rep. 2011, 11, 160. [CrossRef]

50. MacLean, B.; Tomazela, D.M.; Shulman, N.; Chambers, M.; Finney, G.L.; Frewen, B.; Kern, R.; Tabb, D.L.; Liebler, D.C.; MacCoss, M.J. Skyline: An open source document editor for creating and analyzing targeted proteomics experiments. Bioinformatics 2010, 26, 966-968. [CrossRef]

51. RC Team. R: A Language and Environment for Statistical Computing, R Foundation for Statistical Computing. 2017. Available online: https://www.R-project.org/ (accessed on 13 September 2019).

(C) 2019 by the authors. Licensee MDPI, Basel, Switzerland. This article is an open access article distributed under the terms and conditions of the Creative Commons Attribution (CC BY) license (http://creativecommons.org/licenses/by/4.0/). 